\title{
Época de poda e quebra de dormência em videiras cv. Niagara Rosada
}

\section{Times of prunning and budbreaking in Niagara Rosada vines}

\author{
Marcello Sozim $^{1}$, Fabiano P. Ferreira ${ }^{1}$; Ricardo A. Ayub ${ }^{2 *}$ Renato V. Botelho ${ }^{3}$
}

Resumo

\begin{abstract}
O experimento foi conduzido com o objetivo de verificar a eficiência da combinação de cinco concentrações de cianamida hidrogenada $(\mathrm{CH})$ e quatro épocas de poda, na quebra da dormência e antecipação da colheita da videira 'Niagara Rosada' no município de Ponta Grossa - PR. O delineamento experimental foi em blocos casualizados no esquema fatorial 4 x 5 (épocas de poda x concentrações de $\mathrm{CH}$ ), com 3 repetições e 3 plantas por parcela. Foram analisados a porcentagem de brotação, o número de cachos por planta, a produção por planta e a massa média dos cachos. Houve efeito da aplicação de cianamida hidrogenada no aumento da brotação das gemas apenas para a primeira época de poda (06/08/2007). A primeira época de poda antecipou em uma semana a colheita, embora a ocorrência de geadas tenha prejudicado a produção. $\mathrm{O}$ atraso na época de poda proporcionou um maior número de cachos por planta e a maior produção.
\end{abstract}

Palavras-chave: Vitis spp, cianamida hidrogenada, fitorregulador

\begin{abstract}
This research work had as the aim of verifying the efficiency of five combined concentrations of hydrogen cyanamide $(\mathrm{CH})$ in four consecutive pruning times of sprouting vine and harvest anticipation of 'Niagara Rosada' in the county of Ponta Grossa, PR. The experiment had a factorial design ( 4 x 5) with 3 replications and 3 plants per parcel. The analysis were sprouting percentage, number of clusters per plant, rate of production and average weight per cluster. The effect of $\mathrm{CH}$ was shown only at the first pruned time when sprouting but the occurrence of frosting decreased the yield. The delay in the process of pruning showed a higher number of cluster per plant, which consequently resulted in yield increase.
\end{abstract}

Key words: Vitis spp, hydrogen cyanamide, plant growth regulator

\section{Introdução}

As fruteiras de clima temperado caracterizamse pela queda das folhas no final do ciclo e conseqüente entrada em dormência no inverno, com a drástica redução de suas atividades metabólicas. Para que estas plantas iniciem um novo ciclo vegetativo na primavera, é necessário exposição a certo período de baixas temperaturas (PETRI et al., 1996). Comparadas as outras plantas decíduas, as videiras requerem pouca exposição a baixas temperaturas para sair da condição de dormência. A necessidade de temperaturas abaixo de $7^{\circ} \mathrm{C}$ situase entre 50 e 400 horas, variando em função da cultivar (SOUSA, 1996).

A falta de frio invernal na videira produz efeitos como o atraso na brotação das gemas, diminuição de brotos por sarmento, diminuição de ramos por sarmento, pouca uniformidade e desenvolvimento dos

1 Acadêmicos de Agronomia (UEPG), Bolsista PIBIC/CNPq.

2 Prof. de Fruticultura, Dep. de Fitotecnia,, Universidade Estadual de Ponta Grossa, Ponta Grossa, PR. E-mail: rayub@uepg.br

3 Prof. Adjunto, Dep. de Agronomia, UNICENTRO, Guarapuava, PR.

* Autor para correspondência 
ramos e atraso na maturação das bagas (OR et al., 2002). Isto se traduz em produções tardias, de baixa qualidade e em menor quantidade. Os cultivares que não tem seu período de frio plenamente satisfeito apresentam uma brotação desuniforme, sendo que as gemas apicais, por exigirem menor número de horas de frio, brotam antes e exercem a dominância apical (SOUZA; BÜTTENBENDER; AGOSTINI, 2001). Isto provoca problemas de manejo fitossanitário, produção muito escalonada e dificuldades em manter a arquitetura das plantas, pois altera a estrutura das mesmas (MANFROI et al., 1996).

Segundo Miele e Dall'agnol (1994), observa-se diminuição da dominância apical com a aplicação de cianamida hidrogenada $(\mathrm{CH})$. $\mathrm{O}$ efeito da $\mathrm{CH}$ temse verificado nos mais diferentes processos biológicos e fisiológicos da videira, especialmente na quebra de dormência das gemas, na época de brotação, florescimento e de maturação, como também na produtividade do vinhedo (MIELE, 1991; PIRES et al., 1999). Maraschin, Koller e Silva (1992), em trabalhos com videira cv. Niágara Branca verificaram este efeito, ou seja, antecipação e uniformidade de brotação, bem como elevados valores de produção e antecipação da colheita.

$\mathrm{O}$ mecanismo como a $\mathrm{CH}$ influencia na quebra da dormência ainda não é claro, mas evidências demonstram que ocorre inativação da enzima catalase nas gemas após a sua aplicação (OR et al., 2002). A exposição das gemas ao frio inibe a atividade da enzima catalase, que se encontra presente nas células aeróbicas, que decompõe o peróxido de hidrogênio em oxigênio molecular e água (PINTO et al., 2004). Esta inibição ocorre tanto pelo efeito do frio quanto da aplicação da $\mathrm{CH}$, produzindo um aumento dos níveis de peróxido nos tecidos das gemas da videira. Este aumento inicia um processo de tradução de sinais, com o fim do estado de endodormência das gemas e brotação, assim que as condições forem favoráveis para o início de um novo ciclo (OR et al., 2002; PINTO et al., 2004). Mas nem sempre é desejável a aplicação de $\mathrm{CH}$ para antecipação da brotação, pois em regiões frias, como na Região da Serra do Nordeste/RS, os vinhedos estão sujeitos a geadas primaveris, as quais podem causar danos consideráveis às plantas (MIELE, 1991).

Segundo Sousa (1996), a videira é podada com o fim de equilibrar-se a frutificação e a vegetação. Em princípio, poda-se durante todo o período de repouso vegetativo, ou seja, duas ou três semanas após a queda das folhas até a semana que precede o abrolhamento, observando-se sempre os riscos de geadas tardias (CHAUVET; REYNIER, 1979). A intensidade da poda, ou seja, o número de gemas a deixar por ramo da videira, depende da fertilidade das gemas, característica esta que pode ser definida como a capacidade de diferenciação de gemas vegetativas em frutíferas.

Guerreiro (1997) avaliando a brotação da videira 'Niagara Rosada' submetida à poda de frutificação em diferentes datas no Mato Grosso do Sul, concluiu que as podas realizadas entre um curto intervalo de tempo não afetam a brotação das plantas, porém as realizadas tardiamente resultam em redução desta característica fenológica. Por outro lado, para Maraschin, Koller e Silva (1992), a antecipação da época de poda causou acentuada diminuição na produção da cv. Niagara Branca, o que pode ser explicado pelo reequilíbrio hormonal das plantas após o período de dormência.

Neste contexto, realizou-se este trabalho com o objetivo de verificar a eficiência da combinação de cinco concentrações de $\mathrm{CH}$ e quatro épocas de poda, na quebra da dormência e antecipação da colheita da videira 'Niagara Rosada' na região de Ponta Grossa, PR, na safra 2004/05.

\section{Material e Métodos}

O experimento foi conduzido em vinhedo localizado no município de Ponta Grossa-PR, região Centro-Sul do Estado do Paraná, o qual possui segundo a Empresa Brasileira de Pesquisa Agropecuária (2002), clima $\mathrm{C}_{\mathrm{fb}}$ na classificação de Köeppen, 
coordenadas geográficas de $25^{\circ} 09 \mathrm{~S}$ e $50^{\circ} 00 \mathrm{O}$ e 849 metros de altitude. Foram utilizadas videiras cv. Niagara Rosada enxertadas sobre o porta-enxerto 420-A, no $10^{\circ}$ ano, conduzidas no sistema de pérgola e espaçadas em 2,5 x 1,5 m.

O delineamento experimental foi em blocos casualizados, com tratamentos dispostos em esquema fatorial 4 x 5 (épocas de poda x concentrações de $\mathrm{CH})$, com três repetições e três plantas por parcela. Os níveis do fator primário foram constituídos por quatro épocas de poda nas datas: 06/08/2004 (I), 13/ 08/2004 (II), 20/08/2004 (III) e 27/08/2004 (IV), e o sistema utilizado foi o de poda mista. Logo em seguida, realizou-se a aplicação de cianamida hidrogenada mediante pincelamento das gemas. Para o preparo das soluções, utilizou-se do produto comercial Dormex $^{\text {Ò }}$ (Basf S.A.) contendo 490 g. $\mathrm{L}^{-1}$ do ingrediente ativo.

Os níveis de cianamida hidrogenada, foram às concentrações de: 0,$0 ; 1,0 ; 1,5 ; 2,0$ e $2,5 \%$ de ingrediente ativo.

As seguintes variáveis foram avaliadas:

1. Porcentagem de brotação: Foi avaliada a \% de gemas brotadas em relação ao total de gemas nos ramos da videira. Estas avaliações foram realizadas, para a época (I) 56 dias após aplicação em 01/10/ 2004, para a época (II) 53 dias após aplicação em 05/10/2004, para a época (III) 51 dias após aplicação em 10/10/2004 e para a época (IV) 49 dias após aplicação em 15/10/2004.
2. Número de cachos: em 20/12/2004 contou-se o número de cachos de cada planta.

3. Produção: os cachos de cada planta foram pesados em balança digital obtendo-se os valores em $\mathrm{kg} /$ planta.

4. Massa média dos cachos: estimou-se esta variável a partir da divisão do número de cachos totais pelos valores de produção (kg/planta).

Os dados experimentais foram submetidos à análise de variância para o esquema fatorial e quando da interação significativa, comparação de médias pelo teste de Tukey pd'0,05. Caso contrário efetuou-se a análise de regressão dos fatores independentes. Para as análises estatísticas utilizou-se o programa Estat da Unesp de Jaboticabal.

\section{Resultados e Discussões}

A poda realizada na época (I), sem aplicação de $\mathrm{CH}$, proporcionou menor brotação em relação às outras épocas, evidenciando que nesta condição há a necessidade de se realizar a quebra de dormência artificial. Na época (I) a concentração de $2,0 \%$ de $\mathrm{CH}$ aumentou significativamente a porcentagem de brotação das gemas em relação à testemunha, que por sua vez não se diferiu das demais concentrações (Tabela 1). Ocorreu uma frente fria no início da brotação da época citada, o que pode ter prejudicado a brotação. Segundo Miele (1991), o efeito da $\mathrm{CH}$ na quebra de dormência das gemas e na produtividade do vinhedo pode variar em função das condições climáticas.

Tabela 1. Porcentagem de gemas brotadas de videira Niágara Rosada em função da época de poda e da concentração de cianamida hidrogenada, Ponta Grossa, PR, 2004.

\begin{tabular}{lllll}
\hline $\begin{array}{l}\text { Época } \\
\text { \%C.H. }\end{array}$ & $\mathbf{0 6 / 0 8 / 2 0 0 4}$ (I) & $\mathbf{1 3 / 0 8 / 2 0 0 4}$ (II) & $\mathbf{2 0 / 0 8 / 2 0 0 4}$ (III) & $\mathbf{2 7 / 0 8 / 2 0 0 4}$ (IV) \\
\hline 0,0 & $76,07 \mathrm{Bb}$ & $85,08 \mathrm{Aa}$ & $84,09 \mathrm{Aa}$ & $86,20 \mathrm{Aa}$ \\
1,0 & $81,56 \mathrm{ABa}$ & $84,71 \mathrm{Aa}$ & $88,33 \mathrm{Aa}$ & $84,02 \mathrm{Aa}$ \\
1,5 & $80,09 \mathrm{ABa}$ & $86,53 \mathrm{Aa}$ & $87,35 \mathrm{Aa}$ & $82,60 \mathrm{Aa}$ \\
2,0 & $86,83 \mathrm{Aa}$ & $85,81 \mathrm{Aa}$ & $85,90 \mathrm{Aa}$ & $86,01 \mathrm{Aa}$ \\
2,5 & $83,85 \mathrm{ABa}$ & $84,21 \mathrm{Aa}$ & $81,08 \mathrm{Aa}$ & $88,30 \mathrm{Aa}$ \\
\hline
\end{tabular}

Médias seguidas de mesma letra, maiúscula na coluna e minúscula na linha, não diferem significativamente a 5\% pelo teste de Tukey. 
Na Região de Jundiaí-SP, Pires et al. (1999) constataram que a pulverização das gemas da videira 'Niagara Rosada', com CH, adiantou a brotação das gemas e aumentou a porcentagem de gemas brotadas, o número de cachos e a produtividade por planta. Os melhores resultados foram verificados para as concentrações de $\mathrm{CH}$ entre 1,44 e 1,63\%. No Rio Grande do Sul, Miele (1991) obteve resultados semelhantes em videiras da cv. Cabernet Sauvignon, sendo que as melhores concentrações de $\mathrm{CH}$, para as variáveis estudadas, se situaram entre 1,8 e 1,9\%. Ainda Pires (1991) obteve resultados similares e antecipação do desenvolvimento vegetativo em vinte e um dias.

Como apresentado na Tabela 2, houve uma alteração na data de colheita em função das épocas de poda. As plantas podadas em 06/08/2004 (I) tiveram o início da colheita antecipado em aproximadamente uma semana quando comparadas àquelas podadas em 27/08/2004 (IV).

Tabela 2. Efeito das épocas de poda e concentrações de cianamida hidrogenada na antecipação da colheita em videira Niágara Rosada em Ponta Grossa, PR, na safra 2004/05.

\begin{tabular}{|c|c|c|c|c|}
\hline Época & $06 / 08 / 2004$ & $13 / 08 / 2004$ & 20/08/2004 & $27 / 08 / 2004$ \\
\hline \%С.Н. & & ÉPOCA & COLHEITA & \\
\hline 0,0 & $05 / 01-07 / 01$ & $07 / 01-13 / 01$ & $08 / 01-24 / 01$ & $12 / 01-21 / 01$ \\
\hline 1,0 & 03/01-07/01 & 06/01-17/01 & $11 / 01-17 / 01$ & $11 / 01-24 / 01$ \\
\hline 1,5 & 05/01-06/01 & 05/01-08/01 & $08 / 01-4 / 01$ & $12 / 01-19 / 01$ \\
\hline 2,0 & $03 / 01-06 / 01$ & 05/01-10/01 & 08/01-17/01 & $11 / 01-24 / 01$ \\
\hline 2,5 & $03 / 01-06 / 01$ & $05 / 01-17 / 01$ & $11 / 01-17 / 01$ & $11 / 01-17 / 01$ \\
\hline
\end{tabular}

A massa média dos cachos apresentou aumento linear em função da época de poda (Figura 1). Para as plantas podadas em 06/08/2004 (I) e 13/08/2004 (II) o peso médio de cachos foi significativamente menor do que quando podadas mais tardiamente (épocas III e IV), reflexo direto das frias manhãs de primavera, características da região sul do Brasil. Estas baixas temperaturas são responsáveis pelo baixo vingamento de flores, prejudicando a massa média dos cachos das plantas podadas antecipadamente. Botelho, Pires e Terra (2002), também obteve cachos menores nas plantas podadas precocemente.

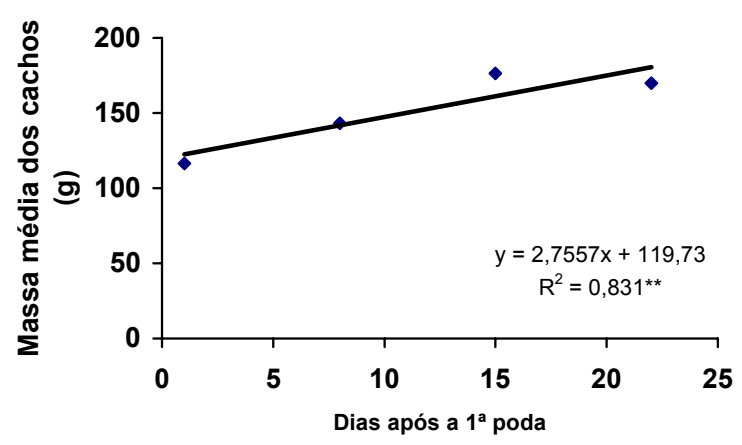

Figura 1. Efeito da época de poda na massa média dos cachos de videira 'Niágara Rosada' em Ponta Grossa, PR, na safra $2004 / 05$. ** significativo a $1 \%$ de probabilidade. Primeira poda realizada em 06/08/2004.
O número máximo de cachos por planta, 87,85 , foi estimado para a poda realizada 14,5 dias em relação ao início do experimento, correspondendo à terceira época de poda. Isto provavelmente se deve a uma melhor condição climática após 13 de Agosto, com aumento sensível da temperatura.

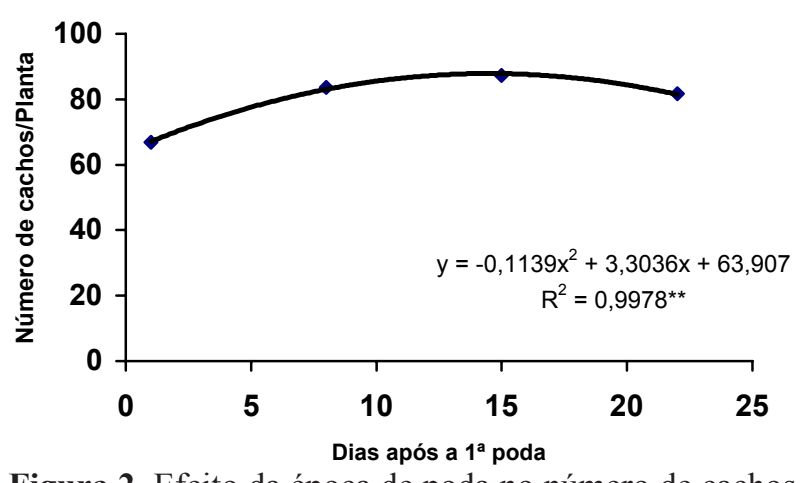

Figura 2. Efeito da época de poda no número de cachos por planta de videira 'Niágara Rosada' em Ponta Grossa, PR, na safra 2004/05. ** significativo a $1 \%$ de probabilidade. Primeira poda realizada em 06/08/2004.

A Figura 3 mostra um crescimento quadrático da produção em função da época de poda. Em 20/08/ 2004 (III) obteve-se maior massa média e maior número de cachos, com conseqüente maior produção. 
A menor produção nas duas primeiras épocas devese a paralisação no crescimento de brotos devido às baixas temperaturas, havendo ocorrido geada nos dois dias após a quebra de dormência. Além disto, na terceira época, as plantas tiveram mais tempo do que as da primeira e segunda época de poda para reequilíbrio hormonal (MARASCHIN; KOLLER; SILVA, 1992) e ainda, o número de horas de frio satisfeito. A queda na produção na quarta época pode estar relacionada a intempéries na época de colheita, ou mesmo a uma variação natural entre plantas.

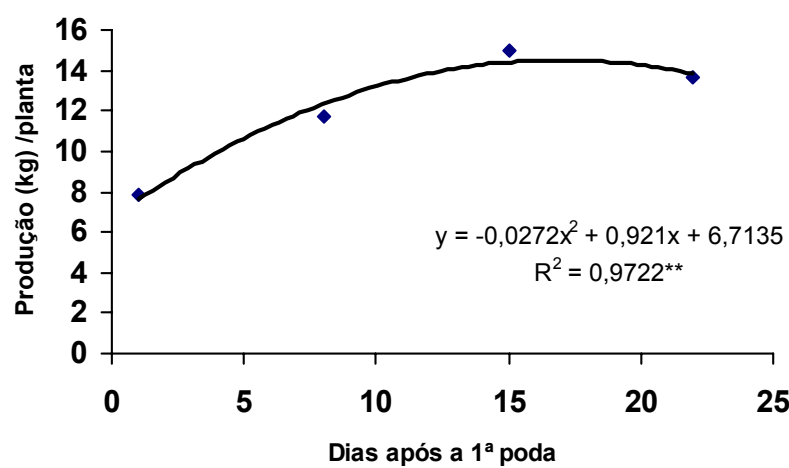

Figura 3. Efeito da época de poda na produção por planta de videira 'Niágara Rosada' em Ponta Grossa, PR, na safra $2004 / 05$. ** significativo a $1 \%$ de probabilidade. Primeira poda realizada em 06/08/2004.

Não houve resposta à dose de $\mathrm{CH}$ para a massa média dos cachos, número de cacho e produção (dado não demonstrado). Contrariamente, Botelho, Pires e Terra (2002) obtiveram resposta para a produção em função da dose de $\mathrm{CH}$ para a cv. Centennial Seedless podada em Abril. Isto comprova a baixa exigência de frio da cv. Niagara Rosada para inicio da brotação, sendo Ponta Grossa uma região com temperaturas suficientes para emissão de novas brotações a partir de meados de Agosto.

\section{Conclusões}

1. A maior produtividade foi verificada para a terceira época de poda, sendo, portanto, a mais indicada para a videira 'Niagara Rosada' cultivada nas condições da região Central do Estado do Paraná.
2. Nestas condições não é aconselhável realizar a poda precocemente devido aos riscos de geadas na região de Ponta Grossa, PR.

\section{Referências}

BOTELHO, R. V.; PIRES, E. J. P.; TERRA, M. M. Brotação e produtividade de videiras da cv. Centennial Seedless (Vitis vinifera L.) tratadas com cianamida hidrogenada na região noroeste do estado de São Paulo. Revista Brasileira de Fruticultura, Jaboticabal, v.24, n.3, p.1-12, 2002.

EMPRESA BRASILEIRA DE PESQUISA AGROPECUÁRIA. 2002. Título. Disponível em $<$ http:// www.cnpf.embrapa.br/servicos/publicacoes/gratuita/ b o 1 e $\mathrm{t}$ i m P D / B P D \% 20001 2002_Parana_Central_Area8\%20.PDF>. Acesso em: 01 ago. 2005

GUERREIRO, V. M. Avaliação fenológica da videira (Vitis labrusca L. $x$ Vitis vinifera L.) cultivar Niagara Rosada na região de Selvíria-MS. 1997. Dissertação (Mestrado em Agronomia)- Faculdade de Engenharia de Ilha Solteira, Universidade Estadual Paulista, Ilha Solteira.

MANFROI, V.; MARODIN, G. A. B.; SEIBERT, E.; ILHA, L. L. H.; MOLINOS, P. R.. Quebra de dormência e antecipação da colheita em videira cv. Niagara Rosada. Revista Brasileira de Fruticultura, Cruz das Almas, v.18, n.1, p.65-74, 1996.

MARASCHIN, M.; KOLLER, O. C.; SILVA, A. L. Efeito da época de poda e calcionamida na quebra de dormência e produtividade da videira cv. Niágara Branca, no litoral catarinense. Pesquisa Agropecuária Brasileira, Brasília, v.27, n.3, p.455-462, 1992.

MIELE, A. Efeito da cianamida hidrogenada na quebra de dormência das gemas, produtividade do vinhedo e composição química do mosto da uva Cabernet Sauvignon. Pesquisa Agropecuária Brasileira, Brasília, v.26, n.3, p.315-354, 1991.

MIELE, A.; DALLAGNOL, I. Efeito da cianamida hidrogenada na quebra de dormência da videira cv. Trebbiano submetida a dois tipos de poda. Revista Brasileira de Fruticultura, Cruz das Almas, v.16, n.1, p.156-165, 1994.

OR, L.; VILOZNY, I.; FENNELL, A.; EYAL, Y; OGRODOVITCH, A. Dormancy in grape buds: isolation and characterization of catalase DNA and analysis of its expression following chemical induction of bud dormancy release. Plant Science, Limerick, v.162, n.1, p.121-130, jan. 2002. 
PETRI, J. L; PALLADINI, L. A; SCHUCK, E; DUCROQUET, J. P.; MATOS, C. S.; POLA, A. C. Dormência e indução da brotação de fruteiras de clima temperado. Boletim Técnico da EMBRAPA/Epagri, Florianópolis, v.75, p.1-110, 1996.

PINTO, M.; LIRA, W.; UGALDE, H.; PÉREZ, F. Fisiología de la latencia de las yemas de vid: hipótesis actuales. 2004. Disponível em: <http://www.gie.uchile.cl/pdf/

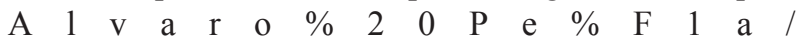

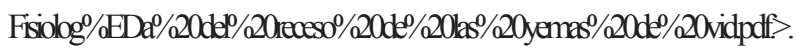
Acesso em: 20 mar. 2005.

PIRES, E. J. P.. Efeito de agentes químicos na indução da brotação, desenvolvimento dos ramos e na produção da videira - cv. Niagara Rosada. In: WORKSHOP DORMEX, 1991, Vitória. Anais... Vitória: BASF/SKW, 1991.p.26.
PIRES, E. J. P.; POMMER, C. V.; TERRA, M. M.; PASSOS, I. R. S. Effects de la cyanamide de calcium et de la cyanamide hydrogéne sur la levée de dormance des bourgeons, le débourrement et le rendement du cépage Niagara Rosé dans la région de Jundiaí, État de São Paulo, Brésil. Bulletin de L'O.I.V., Paris, v.72, n.821/822, p.457483, 1999.

SOUSA, J. S. I. Uvas para o Brasil. 2.ed. Piracicaba: Fealq, 1996.

SOUZA, P. V. D.; BÜTTENBENDER, D; AGOSTINI, S. Influência da época de poda e da quebra de dormência sobre a fenologia e produção da cv. Niágara Rosada na Depressão Central do Rio Grande do Sul. In: VITICULTURE AND ECOLOGY LATIN-AMERICAN CONGRESS, 8., 2001, Montevideo. Anais... Montevideo, 2001. 